\title{
Juventudes, moratória social e gênero: flutuações identitárias e(m) histórias narradas ${ }^{1}$
}

\section{Youths, social moratorium and gender: identity fluctuation and/in narrated stories}

\author{
Sandra dos Santos Andrade ${ }^{2}$ \\ Dagmar Estermann Meyer $^{2}$
}

\begin{abstract}
RESUMO
$\mathrm{O}$ artigo desdobra-se de uma pesquisa inscrita nos campos dos estudos de gênero e culturais em articulação com o pós-estruturalismo foucaultiano, que focalizou a relação entre juventudes e processos de escolarização. $\mathrm{O}$ trabalho de campo incluiu entrevistas narrativas realizadas com 19 jovens, observações do espaço escolar e discussões em grupo com estudantes da Educação de Jovens e Adultos (EJA) de uma escola estadual da periferia de Porto Alegre/RS. Aqui, apresentamos uma análise cultural das narrativas juvenis, na qual problematizamos o conceito de moratória social para discutir relações entre juventude, moratória social e gênero. Nessa análise, o processo de escolarização emergiu como um forte componente da moratória e como o lugar onde se ancoram as experiências que importam, na perspectiva dos/ as próprios/as jovens, quando se trata da constituição de seu futuro, de seu vir a ser. Evidenciou-se, também, que a juventude se oferece de modo diferente a jovens homens e mulheres e que elas e eles vivem a moratória em tempos e de modos distintos, principalmente quando ao gênero se articula a dimensão de classe.
\end{abstract}

Palavras-chave: estudos de gênero; juventude; moratória social; pós-estruturalismo; educação de jovens e adultos.

DOI: $10.1590 / 0104-4060.36463$

1 O artigo é uma versão modificada de um trabalho apresentado no GT Gênero Sexualidade e Educação, durante a 36 Reunião Anual da Anped, realizada em Goiânia, em outubro de 2013, com o título Juventudes contemporâneas e alguns de seus marcadores identitários: histórias narradas.

2 Universidade Federal do Rio Grande do Sul. Programas de Pós-Graduação em Educação e em Saúde Coletiva. Porto Alegre, Rio Grande do Sul, Brasil. Av. Paulo Gama, nº 110 - Farroupilhas. CEP: 90040.060 . 


\begin{abstract}
The article unfolds from a research enrolled in the fields of gender and cultural studies in conjunction with Foucauldian post-structuralism, which focused the relation between youths and schooling processes. The fieldwork included narrative interviews conducted with 19 youngsters, observations of the school space and group discussions with students of Youth and Adult Education (Educação de Jovens e Adultos - EJA) from a State School located in the outskirts of Porto Alegre/RS. We present here a cultural analysis of juvenile narratives, in which we problematize the concept of social moratorium in order to discuss relations between youth, social moratorium and gender. In this analysis, the schooling process emerged as a strong component of the moratorium and as the place where experiences that matter from the perspective of youngsters are anchored, concerning their future and their becoming. It was also evident that youth offers itself differently to young men and women and that they live the moratorium in diverse times and ways, especially when the dimension of class is articulated to gender.
\end{abstract}

Keywords: gender studies; youth; social moratorium; post-structuralism; youth and adult Education.

\title{
$O$ texto em contexto
}

Diferentes instâncias têm buscado exaustivamente definir, categorizar e dizer, detalhada e objetivamente, sobre a juventude, como se isso fosse possível ou necessário. Algumas delas afirmam que a juventude compreende uma fase marcada por processos de definição e inserção social, que é o momento da escolha profissional, de ingresso no mercado de trabalho, de participar de espaços de lazer antes não permitidos, de consumir determinados tipos de produtos, de responsabilizar-se pela organização do seu dinheiro etc. Neste momento, também, o/a jovem começa a ser visto/a como membro economicamente ativo da sociedade. Em algumas vertentes de áreas como a psicologia e a biologia, o sujeito jovem é pensado como um ser que, biológica, mental e socialmente, "progride" da fase infantil para a fase adulta, consistindo a juventude em uma fase intermediária. Ou seja, ela seria o período que marca a passagem da infância para a vida adulta, em uma visão notadamente evolucionista do indivíduo.

Os ditos sobre juventude podem colocá-la, ainda, numa posição de muita positividade: as pessoas não querem mais envelhecer e buscam prolongá-la indefinidamente; e aparentar ser jovem tem sido representado como uma qualidade do sujeito adulto/idoso que, ao manter-se jovem, estaria demonstrando 
disciplina, controle, autogoverno, cuidado de si (COUTO; MEYER, 2011). Nessa perspectiva, a juventude vem carregada de uma ideia de energia, rapidez, saúde e habilidades que perdemos com o passar do tempo. Em outro extremo, os ditos carregam vários sentidos de negatividade: a juventude pode ser perigosa, difícil, uma posição implicada com vulnerabilidades e riscos. Toda essa discursividade permite, pois, dizer que a juventude se tornou um tema da (na) moda que, política e economicamente, interessa à educação, à saúde, à psicologia, à mídia e também ao mercado de consumo, que vê neste segmento um negócio, um consumidor em potencial - de roupas, alimentos, músicas, marcas, imagens e os mais diversos objetos.

Compreendemos, então, juventude como uma condição histórico-cultural, como uma representação (ou como representações) não dada e não fixa. $\mathrm{E}$, como toda construção social, deve ser analisada em suas diferentes dimensões - materiais, políticas, históricas, culturais -, já que estas acarretam modos particulares de compreender a juventude e de ser jovem.

Nessa direção, o gênero é uma das importantes modalidades de nomeação, inscrição e pertencimento que definem o que a juventude é e pode vir a ser. Como construto social que é, trabalhar com o viés de gênero significa considerar que, ao longo da vida e através de diversas instituições e práticas sociais, nos constituímos como homens e mulheres, num processo instável que não é linear, progressivo ou harmônico, e que nunca está finalizado ou completo. Opera-se com o pressuposto de que há uma articulação intrínseca entre gênero e educação e, também, com uma ampliação da noção de educativo, considerando que os processos que nos educam como sujeitos de gênero envolvem estratégias sutis e refinadas de naturalização e legitimação que precisam ser reconhecidas, demarcadas e problematizadas. Além disso, admite-se a existência de formas plurais, conflitantes, ambíguas e instáveis de feminilidade e masculinidade, e se enfatizam a pluralidade e a conflitualidade dos processos pelos quais a cultura constrói e distingue corpos e sujeitos como femininos e masculinos, através da articulação de gênero com outras "marcas" sociais, tais como classe, raça/etnia, sexualidade, geração, religião, nacionalidade. E, ainda, que cada uma dessas articulações produz modificações importantes nas formas pelas quais feminilidades e masculinidades, no plural, são (ou podem ser) vividas e experienciadas por grupos diversos, dentro dos mesmos grupos e, ainda, pelos mesmos indivíduos, ao mesmo tempo ou em diferentes momentos de sua vida (MEYER, 2010).

Com esses pressupostos e a partir desses pontos de vista, este artigo discute o conceito de moratória social, tomando como sujeitos desta moratória jovens das classes populares. Para isso, dialogamos com Urresti e Margulis (1996) que, desde outra perspectiva teórica, problematizam e discutem o conceito de um lugar que nos permitiu fazer uma análise cultural de narrativas juvenis, 
focalizando relações entre juventude, moratória social e gênero. O presente trabalho se desdobra de uma pesquisa desenvolvida por uma de nós como tese de doutorado, inscrita nos campos dos estudos de gênero e dos estudos culturais que vêm exercitando uma articulação crítica com a perspectiva pós-estruturalista ${ }^{3}$, em que se analisou a relação entre juventudes e processos de escolarização (ANDRADE, 2008). O trabalho de campo que gerou o material empírico analisado foi desenvolvido durante dois semestres letivos. Envolveu a realização de entrevistas narrativas, observações do espaço escolar, bem como discussões em grupo com estudantes da Educação de Jovens e Adultos (EJA) de uma escola estadual da periferia de Porto Alegre/RS, gerando um conjunto de textos que foram explorados a partir da análise cultural. A escola autorizou a realização da pesquisa formalmente, e os/as estudantes, a professora e a diretora entrevistados/as assinaram um Termo de Consentimento Livre e Esclarecido (TCLE). Foram entrevistados/as 19 jovens estudantes ${ }^{4}$ (do que equivale ao quarto ano do Ensino Fundamental) com idades entre 15 e 27 anos. Essas entrevistas narrativas foram analisadas tomando-se como referência as discussões de Larrosa (1994) e Foucault $(2000,2002)$.

Nesta análise, utilizamos ainda o conceito de moratória social para concordar com ele, mas também para tensioná-lo, colocá-lo em dissensão, flexibilizá-lo e sugerir outros modos de pensar a juventude nessa relação, desnaturalizando determinados modos de ver/ser um jovem. Nesse exercício de análise, a escolarização emergiu como um forte componente da moratória e como o lugar onde se ancoram as experiências que importam, na perspectiva dos/as próprios/as jovens, quando se trata da constituição de seu futuro, de seu vir a ser.

\section{Flutuações identitárias}

Tradicionalmente, a transição da juventude para a vida adulta é marcada por um complexo processo que abarca a passagem pela escola, a inserção no mercado de trabalho, uma nova constituição familiar, filhos e casamento, o que supostamente sinaliza a independência do/a jovem e a entrada na vida adulta. Essas inserções podem ser modificadas ao longo da trajetória de vida e algumas nem chegam a se efetivar. Não há como prever idades em que esses processos e

3 Neste artigo, optamos por não fazer uma discussão conceitual no sentido estrito do termo; em vez disso, operamos dentro dessa perspectiva teórica e utilizamos seu vocabulário e gramática, ao longo da análise e da argumentação. Para ter acesso à discussão conceitual, ver Andrade (2008).

4 Os nomes aqui utilizados para identificá-los são fictícios. 
inserções poderão ocorrer, até porque ocorrem em tempos diferentes para cada um/a, em função de pertencimentos como gênero, raça e classe, dentre outros.

A idade não se constituiria, então, como um dado biológico, mas seria um construto processado pela história e pela cultura, conectando-se com, e traduzindo-se como um pertencimento geracional. Os pertencimentos geracionais de raça, de gênero e de classe colaboram de modo importante para ponderações em torno da juventude, no entanto, isso não ocorre de modo unidirecional. E elas não se constituem em si mesmas, mas se atravessam. Nessa direção, pela sua insuficiência, a faixa etária que comumente demarca ou identifica a juventude não se configurou, para a escolha dos sujeitos da pesquisa, como um dado fixo, estável, determinado, preciso ou necessário. Entretanto, se por um lado abrimos mão das idades rigidamente estabelecidas como delimitadores de juventude, por outro não há como esquivar-se da cultura em que vivemos, e esta estabelece etapas etárias como marcadores socialmente aceitos que funcionam como delimitadores de nossas vidas.

Esta escrita desloca-se sobre tal conflito, mesmo porque os/as próprios/as jovens da pesquisa veem-se inseridos em uma determinada etapa; e são, também, capturados e constituídos por esse discurso da cultura. O que demarca de modo mais profundo o referido período nesta análise, além desta tensão, são as condições, as possibilidades individuais e sociais que determinado grupo tem para viver esse tempo dentro dos seus diferentes espaços de pertencimento e, ainda, como vão construindo, a partir dessas possibilidades, as "experiências de si" (FOUCAULT, 1997). Concordamos que a experiência de si "não é um objeto independente que permaneceria imutável, através de suas diferentes representações, mas antes, é a experiência de si a que constitui o sujeito, o eu enquanto si mesmo" (LARROSA, 1994, p. 55). Nessa perspectiva, as narrativas de si constituem um material privilegiado para análise das experiências de cada um/a, e permitem visibilizar, ainda, que "o sujeito mesmo tem uma história" (LARROSA, 1994, p. 55). As experiências de si constituem-se por meio de técnicas de vida, da prática de si, e essa prática constrói-se coletivamente no social, na relação com o outro. A escola pode ser um lugar intensificador dessas relações sociais e constituidora das práticas, das experiências de si.

Sara (15 anos) ilustra em sua fala a ideia de que não há um tempo certo para que experiências ditas juvenis possam ou não ser vividas. Embora recorra a um marcador etário para reforçar o que identifica como ser jovem, a fala permite inferir que essa posição de sujeito está intimamente ligada às experiências que a constituem enquanto sujeito e, ao mesmo tempo, se conecta com os diferentes discursos autorizados a dizer o que é juventude: 
Entrevistadora: Quando é que tu vais ser jovem?

Sara: Com 17 anos.

Entrevistadora: O que vai acontecer lá com 17 ?

Sara: Porque eu acho que vou ter mais cabeça, vou ter uma série bem maior, sei lá a sexta série, porque eu me considero criança, porque eu tenho 15 anos [...]

Estar ou não frequentando uma determinada série parece ter o poder de colocá-la ou tirá-la de um lugar de pertencimento; entretanto, com 15 anos, Sara já poderia estar concluindo o Ensino Fundamental. Perguntamos, nesse momento, se é pela idade que se definem tais questões, ao que ela responde: "Eu acho que é pela idade. Tem gurias que têm 15 anos e se consideram já maior de idade, mas eu não me vejo adulta, nem jovem". Ao mesmo tempo, sua fala indica que não é exatamente a idade a sinalizadora desse pertencimento, e sim o modo como vivemos e o que fazemos de nossa vida, influenciados por esses múltiplos discursos, que vão delimitando "[...] as posições que o sujeito pode ocupar na rede de informações", colocadas em funcionamento na cultura (FOUCAULT, 2000, p. 59). Nas palavras de Foucault (1997, p. 109), “[...] a experiência que se pode fazer de si mesmo e o saber que se pode fazer de si mesmo", em certas circunstâncias e em diferentes instâncias institucionais e culturais, indica como alguém se torna objeto de conhecimento admissível ou desejável, graças a relações de controle, domínio e governo de si.

Os/as jovens são oriundos/as de espaços geográficos e famílias diferentes, travam variadas relações sociais, afetivas e culturais e com isso produzem distintas experiências de si. A experiência de si, para Larrosa, não depende nem do objeto nem do sujeito. Para ele, "a experiência é o que ocorre 'entre' e o que constitui e transforma ambos" (1994, p. 83). A história da experiência de si está atrelada a um domínio material, como a própria juventude, por exemplo.

Ao fazer referência à escola em sua fala, a jovem permite inferir que este é um dos espaços importantes de delimitação da experiência da juventude, mesmo sabendo-se que outros espaços da cultura exercem influência na constituição das juventudes. Suas palavras possibilitam pensar a escola como uma daquelas instâncias que estabelecem e/ou transformam a experiência que os indivíduos produzem de si mesmos, através dos múltiplos discursos que ela tanto produz quanto reproduz e atualiza, uma vez que a escola está atrelada a um conjunto de saberes e de práticas muito concretas que estão vivas nesses discursos e que expressam algumas verdades de nosso tempo.

Margulis e Urresti (1996) destacam, em seus textos, um certo prolongamento da juventude na atualidade - que eles chamam de moratória social -, 
em função mesmo da ambiguidade das fronteiras etárias, dos deslocamentos, das experiências, das transformações, da demora e da incompletude de certas vivências, da inserção em (e transição por) processos como os já citados. Vivemos, com isso, o borramento de delimitações que antes pareciam muito mais precisas entre infância e juventude e entre juventude e vida adulta. Entendemos que esse prolongamento da juventude tem afetado os/as jovens de modo geral, embora de diferentes formas e por motivos distintos. Entre os principais fatores dessa moratória podem-se destacar: transformações no mundo do trabalho que retardam o ingresso do/a jovem no mercado de trabalho e exigem dele/a cada vez mais qualificação e/ou escolarização; consequentemente, maior tempo de permanência na casa da família e casamentos e/ou filhos mais tardiamente elementos, dentre outros, que colaboram para constituir as experiências de cada um/a. Esses elementos também integram discursos distintos que funcionam produzindo "[...] formas de experiência de si nas quais os indivíduos podem se tornar sujeitos de um modo particular" (LARROSA, 1994, p. 57). Como nos sinaliza Andressa, na fala abaixo transcrita, também podem se tornar mulheres de um modo particular. Em sua fala evidenciam-se, ainda, outros elementos desta juventude prolongada, que se fizeram visíveis nas diversas entrevistas realizadas:

Andressa (17 anos): Porque todo mundo fala que quer ser gente grande, mas é bom ser jovem.

Entrevistadora: O que é ser jovem?

Andressa: Isso aí, tu te acostumar com pessoas da tua idade que ainda não têm essa responsabilidade, é muito cedo.

Entrevistadora: Que diferenças tu acha que vão acontecer na tua vida quando tu virar adulta?

Andressa: Vou ter que ter mais responsabilidade; vou ter que ter marido; vou ter que cuidar da minha casa, dos meus filhos. Tão cedo eu não quero filhos, e acho que é isso mesmo ser jovem.

A nosso ver, os/as jovens informantes expressam, nessas falas acerca de seu modo de viver e ver o mundo, um tipo de moratória social, embora Margulis e Urresti (1996) considerem que para as classes populares essa condição de moratória seja quase inexistente. Os autores consideram que o conceito de "moratória social" caracteriza a possibilidade oferecida por determinados grupos sociais (principalmente de classe média) a seus/suas jovens, como um “tempo legítimo para que se dediquem ao estudo e à capacitação [profissional], postergando o matrimônio [ou a vida independente, fora da casa dos pais], o 
que lhes permite gozar de certo período durante o qual a sociedade lhes brinda com uma especial tolerância" (MARGULIS; URRESTI, 1996, p. 15). Temos clareza de que essas modalidades não se manifestam do mesmo modo nas diferentes classes sociais, entretanto, esta pesquisa indica que os/as jovens de classes populares também usufruem certo período de moratória, mesmo que ela seja vivida de outros modos.

Os/as jovens, mesmo nas faixas de renda mais baixas, também vivem a chamada moratória social, uma vez que reforçam em suas falas o pensamento usual de que sair da juventude acarreta ter responsabilidades de outra ordem, ter um novo lar, marido e filhos, apontando, ao mesmo tempo, experiências bastante específicas de cada gênero, relacionadas ao mundo afetivo, ao trabalho, à inserção social etc. Ou seja, as referências a diferenças biológicas e aos "destinos" sociais que elas sustentariam ainda servem de explicação amplamente aceita para dizer sobre alguns dos posicionamentos e trajetórias estabelecidos para homens e mulheres em nossa sociedade, por exemplo. Andressa parece não questionar um certo "destino de gênero" que, culturalmente, continua funcionando, com mais ou menos força, para as mulheres: casar e ser mãe. Mas, ao mesmo tempo, ela deixa implícito que esses processos e essas posições acarretam responsabilidades e, talvez, impedimentos para os sonhos que alimenta de fazer faculdade e ser médica; sinaliza, entretanto, que hoje esse destino pode ser adiado. Observamos, ainda, que a maioria dos/as jovens é solteira/o, sem filhos e dependente da família de origem; aliás, nesse contexto, muito frequentemente, até quando se casam ou têm filhos, continuam morando na casa ou no terreno da família e contando com o auxílio financeiro e os cuidados desta. Se, por um lado, isso pode ser entendido como decorrência de condições sociais adversas e desiguais, não se poderia, também, pensar que esta seria, ao mesmo tempo, uma possibilidade de se viver a moratória entre jovens das classes populares?

Assim, pode-se dizer que os/as jovens da pesquisa, embora não integrem as chamadas classes médias, também vivem a moratória como adiamento, suspensão e/ou reinserção em "contextos adultos", e em diferentes momentos de sua vida. Isso ocorre porque gênero e classe são modalidades de pertencimento que não remetem a um grupo estável ou fixo, mas a uma condição social e culturalmente produzida, marcada por formas diversas de inserção e diferenciação, passando a significar, a um só tempo, "[...] condição social, grupo de status atribuído, grupo de interesses e forma de identidade social" (GUIMARÃES, 2002, p. 47).

Andressa, por exemplo, mora com a mãe e mais três irmãos, nunca trabalhou e acha que precisa estudar mais para conseguir um trabalho melhor, pois não quer ser faxineira como a mãe que, segundo ela, precisa trabalhar muito para dar conta de sustentar a família sem a ajuda do pai. Foi comum ver rapazes e moças, ainda bem jovens, recém-chegados ao ensino da EJA, sem experiência 
no mundo do trabalho, sem filhos, vivendo com suas famílias e confiantes na escola como via de acesso para um "futuro melhor". Tais relatos sustentam a suposição de que a experiência da moratória social tem se alargado para abarcar distintos segmentos sociais e um leque mais amplo de experiências, em função também de uma crise econômica e social que vem marcando e rearranjando os espaços de pertencimento nestes tempos ditos pós-modernos.

Andressa diz que seu objetivo é estudar para ser médica, trabalhar e ser alguém na vida, mas tem medo de não conseguir e, por isso, faz também curso de padaria $^{5}$. Ela não quer trabalhar com isso, mas acredita que ter o certificado do curso pode auxiliar em caso de necessidade. Isto é, apesar de se saber jovem, de ter claro o desejo de que esta juventude perdure por um longo tempo, que não quer seguir os passos de sua mãe (que teve filhos muito jovem, sem companheiro e com situação profissional precária), a moça tem certa consciência das dificuldades que enfrenta e vai enfrentar para atingir seu objetivo de crescimento pessoal e profissional, principalmente, por ser mulher e pobre. Larrosa fala em uma prática educativa de educação moral. É a partir desse conceito que talvez possa ser pensada a reflexividade encontrada nas falas de alguns/algumas jovens em torno de sua constituição enquanto tal. Diz o autor que tal prática educativa aparece "[...] definindo de forma singular e normativa o que significa autoconhecimento enquanto experiência de si e como produzindo as relações reflexivas que o tornam possível" (1994, p. 57).

Essa autorreflexão pode ser vislumbrada através do uso dos verbos "vou" e "ter"; ambos aparecem na expressão "vou ter que", repetidamente enunciada por Andressa. Na expressão, as palavras implicam uma ação, um empreendimento, um imperativo, algo do qual não se pode escapar: marido, casa, filhos, trabalho... Estes se colocam como condições quase inevitáveis ao ser adulto e como destino feminino, e parecem fazer parte de um projeto de vida preestabelecido, inquestionável, o qual se pode, ao mesmo tempo, adiar, pois, como diz a entrevistada, "é muito cedo ainda para ter certas responsabilidades". Está indicado aí o que Larrosa chama de "[...] tomada de consciência como transformação da experiência de si [que] é normativamente e praticamente produzida" principalmente através de estratégias pedagógicas, como as narrativas pessoais na educação de jovens e adultos, por exemplo $(1994, \text { p. } 58)^{6}$.

5 O curso de padaria é oferecido gratuitamente no bairro a jovens pobres, através da parceria com diferentes entidades, inclusive com a Prefeitura Municipal.

6 Era habitual ver a solicitação, nas atividades pedagógicas da EJA, de que os/as alunos/as falassem de si, de suas experiências e histórias pessoais, como em uma atividade na qual um texto foi utilizado para desencadear uma discussão sobre os sonhos individuais, e cada um/a deveria posicionar-se frente a isso, falar de suas expectativas de futuro. 
O enunciado implícito na fala de que ser adulto (e mulher) é ter mais responsabilidade, marido, casa, filhos e um trabalho visibiliza como se processa uma "reflexividade normativamente construída", evidenciando que os discursos pedagógicos (escolares ou não) são capazes de fabricar o sujeito, "[...] definido normativamente em termos de autoconsciência e autodeterminação" (LARROSA, 1994, p. 40). Levando em conta que estas falas são o resultado do entrecruzamento de discursos de distintas ordens, os/as jovens, ao enunciarem "tenho muitos anos pela frente", são subjetivados pela ideia de que este é o período para que determinadas coisas sejam feitas, para que determinados comportamentos possam ser aceitos, corrigidos ou vivenciados.

Outro entrevistado diz que ser jovem é legal porque "dai não trabalha ainda, fica estudando" (Luan, 15 anos), o que sinaliza outra possibilidade de moratória. E para Eliane, uma jovem de 24 anos, ser jovem é ter "tanta coisa para aprender, pra mim passar pra alguém, ensinar sabe, pras pessoas que não sabem... Aí, acho que não fiz nem a metade ainda, né”. Pode parecer que há certa ambiguidade nos discursos que orientam estas duas falas, talvez em função mesmo das experiências que cada um foi vivendo ao longo de sua vida.

Inicialmente, sem conhecer a história de vida desses dois jovens, poder-se-ia dizer que pensam de modos diferentes sobre a juventude por possuírem idades diferentes, mas exatamente estas falas nos permitem relativizar essa interpretação e pensar na constituição do sujeito a partir da experiência de si. Luan e Eliane possuem responsabilidades e experiências de vida muito distintas entre eles. As experiências sociais que se vivem em determinados grupos culturais vão dizendo muito de nós e do outro e, ao mesmo tempo, indicam que ser homem e mulher jovem também não é, sob muitos aspectos, a mesma coisa. Parece-nos que, para Eliane, que já é mãe, o "ter muito a ensinar para quem não sabe", como um sentido para ser jovem, está estreitamente atrelado à sua experiência materna de cuidado, educação e proteção e às aprendizagens que fez em torno disso; está atrelado também ao fato de ter um emprego com carteira assinada em um supermercado da cidade e ter conquistado neste emprego uma posição que considera privilegiada em relação àquela que possuía quando entrou na empresa (é, hoje, arquivista). Acreditamos, ainda, que a morte prematura do pai tenha produzido modos diferenciados de ver a vida, pois a partir desse acontecimento a família teve que ser reorganizada para poder sobreviver sem o pai, que era o provedor de todos na época, fato que, segundo Eliane, foi um dos motivadores de sua saída da escola.

Para Luan, o sentido de ser jovem está atrelado a outras experiências de vida, sendo organizado por outros discursos, pelo tempo na escola sem trabalhar, sem assumir compromissos e responsabilidades considerados da vida adulta, 
resultado de uma "combinação" feita na família, um período "legítimo" de moratória social.

A pulverização, dispersão e multiplicidade dos ditos em torno da noção de juventude produzem também nos jovens, ao dizerem de si, diferenças, ambiguidades e diferentes possibilidades. Talvez este seja um efeito da polifonia do termo. A mídia, a pedagogia, a psicologia, a política, a publicidade etc. produzem a juventude como prática social e como artefato (pedagógico/político/social/cultural). Enquanto construto, ela é constantemente (re)construída nessas discursividades que buscam dizer "a verdade" sobre ela. Adquire uma materialidade que é, ao mesmo tempo, produto do poder e que gera poder e divisões sociais ancoradas em marcadores identitários como classe e gênero, por exemplo. A inserção da juventude nessa rede de saberes que dizem sobre ela estabelece, também, outras e novas relações de poder.

O poder, entendido aqui na perspectiva foucaultiana, tem funcionado como um organizador de sistemas de classificação - sociais, culturais, políticos, econômicos - ajudando cada um/a a reconhecer-se em determinadas representações e a ocupar determinadas posições. Interfere e organiza a rede de saberes que se produz em torno da juventude, através da hierarquização desses saberes. $\mathrm{O}$ poder, no entanto, não possui uma realidade ou uma essência, “[...] não existe algo unitário e global chamado poder, mas unicamente formas díspares, heterogêneas, em constante transformação" (MACHADO, 1993, p. x). E, se a noção de juventude é resultado de relações de poder que disputam legitimidade sobre ela, então esta não pode ser definida de uma vez pra sempre; é uma prática social como qualquer outra, constituída historicamente.

Entrevistadora: O que é legal de ser jovem?

Luan (15 anos): Não trabalhar ainda, ficar estudando.

Entrevistadora: Que mais?

Luan: Só. É bom ser velho, ter 18, aí dá pra fazer tudo que o cara quiser.

Qual é a noção de juventude que vem agregada a esta fala? O que é ser jovem para estes jovens, especificamente? A ideia de ficar mais velho parece agregar, para alguns, melhores possibilidades e valores. Para outros, a adultez aparece como lugar da impossibilidade. E por que ter 18 anos já é ser "velho"? Como essa noção se conecta com as experiências de futuro, escola, trabalho, quartel etc.?

O modo como a juventude é vivida, especialmente por alguns/algumas desses/as jovens, faz um retorno à infância e aponta para dois extremos ou 
fronteiras fortemente delimitadas: como se tudo (de melhor e de pior) ficasse para quando se chegar à adultez. Em uma das discussões de grupo, entregamos a cada um/a uma tira de papel com a expressão "ser jovem é". Pedimos que completassem a frase, utilizando as linhas pontilhadas como quisessem. Nessa atividade, Cristian (15 anos) escreveu: "Ser jovem é ser criança, poder brincar e amar". Outros escreveram que ser jovem é "ter uma idade certa para sair"; "o começo da vida, que as pessoas começam a descobrir"; "ter mais educação, começa a conhecer". Ou fica a dúvida entre o que é "mesmo" infância e juventude, ou se vê um adiamento da identificação com essa posição de sujeito ou, ainda, deposita-se na juventude uma noção de "vir a ser", como projeção de futuro. É só aí que se começa a trabalhar "de verdade", ter responsabilidades "de verdade", fazer o que se quer "de verdade"...

Destacamos esse "de verdade" porque a representação de que um dia se pode ficar livre para viver a vida como bem entender, como uma espécie de alforria (não sabendo ao certo do que e, ao mesmo tempo, de tudo), integra o discurso do senso comum em nossa cultura. Acreditamos que tal representação está relacionada com o que se constrói em torno da juventude: só se pode votar a partir dos 16 anos, fazer carteira de motorista com 18, se atinge a maioridade legal com 21 etc. Ao mesmo tempo, os/as jovens, aos poucos, vão percebendo que toda autonomia é relativa. Ou seja, as estruturas sociais que operam dentro de certa cultura não são totalmente determinadas por ela e nem são independentes da cultura na qual se constituem.

Em contrapartida, para entrevistadas como Ana (26 anos) e Eliane (24 anos), que trazem consigo um conhecimento e uma experiência de vida bastante diferentes das de outros/as jovens, em função de aprendizagens e situações vividas (algumas muito dolorosas e difíceis), a juventude apresenta-se como um lugar idílico, talvez por não tê-la vivido como julgam (ou como a sociedade nos ensina como sendo adequado) ou como o tempo ideal para a realização de certas coisas:

Entrevistadora: O que tu entendes por ser jovem?

Ana: Disposição, tentar entender o ser humano, o próximo, a idade também influencia e muito. Acho que é isso porque geralmente a pessoa que passa do adulto, do jovem pro adulto já começa a se acomodar, aquela coisa, não quer sair, não quer aquilo, não quer trabalhar, tem preguiça disso, tem preguiça daquilo outro. O jovem não, o jovem tem disposição pra tudo, tanto fez, tanto faz.

Entrevistadora: A juventude pra ti é uma coisa bem positiva, bem legal... Ana: Bah, muito legal, pra mim não precisava ter velhice. 
A fala também reintroduz a colocação de que ser jovem implica ter mais disposição, maiores habilidades, não se acomodar, ter uma aparência entendida em nossa cultura como mais desejável. A juventude aparece como um período que deveria ser o de estar sempre alegre, cheio de energia, afinal é isso o que dela se espera. É a reiteração de certos ditos nos quais ser velho aparece, de um modo geral, como algo negativo, indesejado, já que ser jovem desponta, desde as últimas décadas, como o modo de ser mais cobiçado e valorizado em nossa cultura. Ser jovem envolve atitude, uma condição e uma posição de sujeito que se quer permanente, e isso - como sinalizam as falas destes/as jovens - parece independer de classe social, gênero ou raça.

\section{Moratória social, juventude e gênero - fechamentos provisórios}

A partir do conceito que nos propusemos a problematizar em articulação com juventude e gênero, qual seja, a moratória social na perspectiva de Margulis e Urresti (1996), podemos considerar que esta pesquisa reitera que há tanto mudanças quanto permanências nos modos de viver a juventude nos diferentes grupos sociais. Do ponto de vista das mudanças, os ditos juvenis aqui analisados nos permitem considerar que uma certa forma de moratória social tem sido vivida por jovens das classes populares, estendendo-se, dessa forma, para além das juventudes de classe média. É claro que esse momento de suspensão e/ou de adiamento ocorre por motivos diversos, em tempos diferentes, e é desencadeado por diferentes situações de ordem econômica, social e cultural que são contingentes e contemporâneas. Sara, Andressa, Eliane e Ana, por exemplo, permitem perceber que ser jovem, para elas, é diferente do que ser jovem para Felipe, Cristian e Luan. A juventude parece se oferecer de modo diferente aos jovens homens e às jovens mulheres e, nesse contexto, elas e eles também vivem a moratória de modos e em tempos distintos. Ou seja, a vivência da moratória também se apresenta de modos diferentes de acordo com o gênero no qual os/ as jovens em foco se nomeiam e reconhecem.

Assim, mesmo com uma certa reiteração dos "destinos de gênero", enunciados sobretudo nas falas das jovens, e que muitos estudos sigam evidenciando que mulheres das camadas populares geralmente têm filhos mais cedo e se casam mais cedo, e que isso vai constituir urgências distintas, não é possível negar mudanças evidenciadas nas relações de gênero e nos modos de ver a vida de jovens como Sara e Andressa. E mesmo que, comumente, ainda sejam as mulheres as responsáveis pelo cuidado e pela educação de filhos e 
irmãos pequenos, tendo que, muitas vezes, abrir mão de certas experiências de vida em prol de outras, ou desde cedo conciliar uma dupla jornada de tarefas e responsabilidades, as entrevistadas mostram-se conscientes das implicações que tais responsabilidades e destinos têm sobre a realização de seus sonhos e futuros. Elas conseguem verbalizar a preocupação e a insegurança frente a tais responsabilidades e manifestam o desejo de adiamento desses "destinos", buscando algumas maneiras de concretizá-lo.

Ao mesmo tempo, nenhum dos homens da pesquisa possuía filhos, nem mesmo os mais velhos, e nenhum deles era casado. Já entre as mulheres, seis delas eram mães e três viviam com o companheiro. Assim, mesmo com as transformações sociais ocorridas nas relações sociais de gênero e com tantas conquistas femininas na busca de equalização com os homens no mercado de trabalho e no campo da educação, as questões do campo privado e doméstico ainda dizem mais respeito a elas do que a eles. Ainda parece ser considerado "normal", por exemplo, que uma moça se torne responsável sozinha pelo filho quando engravida, pois foi o que ocorreu com quatro das estudantes que são mães. Parece "normal" que abandonem os estudos para cuidar dos filhos e que assumam uma tripla jornada ao retornar à EJA: trabalho, escola e filhos. Parece "normal" que uma aluna falte à aula para cuidar dele/a. E que considerem a tríade casamento, marido e filhos como destinos que lhes pertencem, mesmo que esses destinos já possam, hoje, ser adiados. Dentro dessa lógica, ainda seria diferente ou estranho uma mãe que não abdicasse de seus estudos e de outros investimentos pessoais em prol dos filhos e, ao mesmo tempo, ainda seria estranho ver um homem assumindo todas essas posições sem a presença feminina.

Nessa direção, os aspectos aqui analisados, dentre outras coisas, nos permitem argumentar que há uma estreita relação entre a constituição dos/as jovens como sujeitos de gênero e os processos educativos. E que os indivíduos aprendem desde muito cedo "[...] a ocupar e/ou a reconhecer seus lugares sociais e aprendem isso em diferentes instâncias do social, através de estratégias sutis, refinadas e naturalizadas que são, por vezes, muito difíceis de reconhecer" (MEYER, 2010, p. 22). E isso demanda a necessidade e a importância de se examinar como e de que modos os diferentes processos e práticas sociais e culturais nos quais os/as jovens se veem envolvidos/as educam-nos/as como homens e mulheres específicos/as e, ao mesmo tempo, ressignificam relações entre juventudes e moratória social. 


\section{REFERÊNCIAS}

ANDRADE, Sandra dos Santos. Juventudes e processos de escolarização: uma abordagem cultural. Tese (Doutorado em Educação) - Programa de Pós-Graduação em Educação, Faculdade de Educação, Universidade Federal do Rio Grande do Sul, Porto Alegre, 2008.

COUTO, Edvaldo; MEYER, Dagmar E. E. Viver para ser velho? Cuidado de si, envelhecimento e juvenilização. Revista da FACED, Salvador, n. 19, p. 21-32, jan./jun. 2011.

FOUCAULT, Michel. Resumo dos Cursos do Collège de France. Rio de Janeiro: Jorge Zahar, 1997. . A arqueologia do saber. Rio de Janeiro: Forense Universitária, 2000. . As palavras e as coisas. São Paulo: Martins Fontes, 2002.

GUIMARÃES Antônio Sérgio. Classes, raças e democracia. São Paulo: Editora 34, 2002.

LARROSA, Jorge. Tecnologias do eu e educação. In: SILVA, Tomaz Tadeu da (Org.). $O$ sujeito da educação: estudos foucaultianos. Petrópolis: Vozes, 1994. p. 35-86.

MACHADO, Roberto. Introdução: por uma genealogia do poder. In: FOUCAULT, Michel. Microfisica do poder. Rio de Janeiro: Graal, 1993. p. vii-xxiii.

MARGULIS, Mario; URRESTI, Marcelo. La juventud es más que una palabra. In: ARIOVICH, Laura. La juventud es más que una palabra: ensayos sobre cultura y juventud. Buenos Aires: Biblos, 1996. p. 13-30.

MEYER, Dagmar E. E. Gênero e educação: teoria e política. In: LOURO, Guacira Lopes; NECKEL, Jane Felipe; GOELLNER, Silvana Vilodre (Org.). Corpo gênero e sexualidade: um debate contemporâneo na educação. Petrópolis: Vozes, 2010. p. 9-27.

Texto recebido em 09 de maio de 2014. Texto aprovado em 19 de maio de 2014. 